\title{
Conformation dependent monoclonal antibodies distinguish different replicating strains or conformers of prefibrillar $A \beta$ oligomers
}

Rakez Kayed ${ }^{1,5}$, Isabel Canto ${ }^{1,2}$, Leonid Breydo ${ }^{1}$, Suhail Rasool ${ }^{1}$, Tamas Lukacsovich ${ }^{3}$, Jessica Wu ${ }^{1}$, Ricardo Albay III , Anna Pensalfini', Stephen Yeung ${ }^{1}$, Elizabeth Head ${ }^{4}$, J Lawrence Marsh ${ }^{3}$, Charles Glabe ${ }^{1 *}$

\begin{abstract}
Background: Age-related neurodegenerative diseases share a number of important pathological features, such as accumulation of misfolded proteins as amyloid oligomers and fibrils. Recent evidence suggests that soluble amyloid oligomers and not the insoluble amyloid fibrils may represent the primary pathological species of protein aggregates.
\end{abstract}

Results: We have produced several monoclonal antibodies that specifically recognize prefibrillar oligomers and do not recognize amyloid fibrils, monomer or natively folded proteins. Like the polyclonal antisera, the individual monoclonals recognize generic epitopes that do not depend on a specific linear amino acid sequence, but they display distinct preferences for different subsets of prefibrillar oligomers. Immunological analysis of a number of different prefibrillar $A \beta$ oligomer preparations show that structural polymorphisms exist in A $\beta$ prefibrillar oligomers that can be distinguished on the basis of their reactivity with monoclonal antibodies. Western blot analysis demonstrates that the conformers defined by the monoclonal antibodies have distinct size distributions, indicating that oligomer structure varies with size. The different conformational types of A $\beta$ prefibrillar oligomers can serve as they serve as templates for monomer addition, indicating that they seed the conversion of $A \beta$ monomer into more prefibrillar oligomers of the same type.

Conclusions: These results indicate that distinct structural variants or conformers of prefibrillar A that are capable of seeding their own replication. These conformers may be analogous to different strains of prions.

\section{Background}

Many age-related degenerative diseases are characterized by the accumulation of amyloid deposits derived from a variety of proteins. There is conflicting evidence for the role of insoluble fibrillar $A \beta$ deposits in Alzheimer's disease (AD) pathogenesis. The extent of insoluble $A \beta$ plaque accumulation does not correlate well with the severity of dementia in AD [1] and a significant fraction of age matched, non-demented individuals have equivalent amounts of $A \beta$ plaques as demented individuals. In addition, some transgenic animals display cognitive deficits prior to the onset of $A \beta$ plaque accumulation [2,3].

\footnotetext{
* Correspondence: cglabe@uci.edu

'Department of Molecular Biology and Biochemistry, University of California, Irvine, CA 92697-3900, USA

Full list of author information is available at the end of the article
}

Soluble $A \beta$ levels correlate better with dementia than insoluble, fibrillar deposits $[4,5]$, suggesting that oligomeric forms of $\mathrm{A} \beta$ may represent the primary toxic species in AD. Indeed, soluble oligomers have been implicated as primary causative agents in many different degenerative diseases where the accumulation of large fibrillar deposits may be either inert or protective (reviewed in [6,7]).

Conformation dependent, aggregation specific antibodies indicate that there are at least 3 structurally distinct general classes of amyloid oligomers: prefibrillar oligomers, fibrillar oligomers and annular protofibrils. Prefibrillar oligomers (PFOs) are kinetic intermediates that occur at early times of aggregation and are recognized by the polyclonal antibody, A11 [8]. Fibrillar oligomers (FOs) appear to be small pieces of fibril protofilaments

\section{Biomed Central}


that are recognized by the fibril specific polyclonal serum, OC $[9,10]$. A11 does not recognize amyloid fibrils or monomers while $\mathrm{OC}$ does not recognize prefibrillar oligomers or monomers [9]. Annular protofibrils (APFs) are ring shaped, pore-like structures that display an epitope that is specifically recognized by $\alpha \mathrm{PF}$ antiserum [11]. These three classes of amyloid oligomers appear to be general and common to many different types of amyloid forming proteins and peptides because A11, OC and $\alpha$ APF antibodies recognize generic epitopes that are displayed by their respective oligomers when formed by many different peptides of varying amino acid sequences.

Many amyloid fibril structures are known to be parallel, in register $\beta$-sheets based on NMR and EPR spectroscopic studies (reviewed in $[12,13]$ ), A $\beta$ fibrils are structurally polymorphic and this variation arises from conformational differences in the folding of the parallel, in register sheet [14-16]. These folding polymorphisms are self propagating and give rise to differences in the quaternary structure of the fibrils resulting in the assembly of fibrils containing 2 or 3 protofilaments [14,16,17]. Yeast prions are also parallel, in register structures $[18,19]$ and exhibit remarkable phenotypic variants or strain behavior that may be based on underlying structural variation of the type observed for amyloid fibrils [20]. PFOs appear to be a class of amyloids that is structurally distinct from amyloid fibrils based on the observation that they are recognized in a mutually exclusive manner by the conformation dependent antibodies A11 and OC $[9,10]$. PFOs also lack strong spin-spin coupling of paramagnetic spin probes that are characteristic of parallel, in-register fibrils $[10,21]$. Since both of these antibodies recognize generic epitopes that are formed by many different amyloidogenic sequences, these differences are likely to be fundamental differences in the organization of the polypeptides in the sheets, implying that PFOs are not parallel, in-register structures that have been established for amyloid fibrils. FTIR spectroscopy indicates that A11 positive PFOs may be antiparallel beta sheets, implying that they are not intermediates on the pathway to the formation of parallel, in-register fibrils [22]. It is not known whether the PFO structures are polymorphic and display the same types of structural variants that have been reported for amyloid fibrils. Since A11 is polyclonal, it is not clear whether its ability to recognize PFOs from many different types of amyloids is a reflection of the commonality of PFO structure or multiple individual antibodies in the population that recognize different sequence specific PFO epitopes.

We isolated a number of different rabbit monoclonal antibodies (Mabs) specific for prefibrillar oligomers. Here we report that these antibodies recognize generic epitopes that are distributed among several prefibrillar oligomer forming sequences and they display distinct preferences for different protein sequences. In different preparations of $A \beta$ prefibrillar oligomers, the monoclonals recognize distinct subtypes, indicating that structural "strains" of prefibrillar oligomers exist. These strains are capable of propagating by seeding the conversion of $A \beta$ monomer into PFOs of the same type. These results demonstrate that amyloid oligomers are more structurally diverse than was previously known and raise the questions of which of these structural variants is more closely associated with disease pathogenesis and whether the variation contributes to disease heterogeneity.

\section{Results}

\section{Prefibrillar oligomer specific monoclonals}

We made prefibrillar oligomer specific monoclonal antibodies using the same strategy we employed to make the A11 polyclonal by vaccinating rabbits with $A \beta 40$ covalently coupled to colloidal gold particles via a carboxyl terminal thiol [8]. Rabbits were chosen primarily because we had limited success in making A11-like monoclonals in mice. In 4 independent fusions using 4 different strains of mice, the only antibodies specific for prefibrillar oligomers were IgMs. The rabbit monoclonals we obtained are predominantly IgG and they have the additional advantage that they are the same species of antibodies as the polyclonal A11. We selected 6 different clones based on their differential immunoreactivities on ELISA (data not shown) and dot blot (Figure 1). Four of the 6 clones recognize generic epitopes in several different PFO-forming sequences, including Mabs 55, 118, 204 and 205, which are all IgG1. These antibodies display distinct preferences for different subsets of PFOs, suggesting that the broader range of A11 immunoreactivity is due to the presence of multiple individual antibody specificities. Mab204 appears to have the broadest generic reactivity because it reacts strongly with all PFOs tested except IgG light chain. These results demonstrate that individual clones are capable of recognizing epitopes that are generically distributed among PFOs formed by different sequences and that the different antibodies recognize different epitopes that are differentially displayed on PFOs formed from different sequences. Mab201 appears to be both conformation and sequence specific because it recognizes only $A \beta$ prefibrillar oligomers. This demonstrates that some of the monoclonals are sequence specific and do not recognize generic epitopes. Antibody 121 recognizes $\mathrm{A} \beta$ fibrils and not prefibrillar oligomers, similar to OC. Both Mab201 and 121 are IgM class antibodies. Because the hybridoma cells secrete very low amounts of IgM, further work was concentrated on the monoclonal IgGs. 


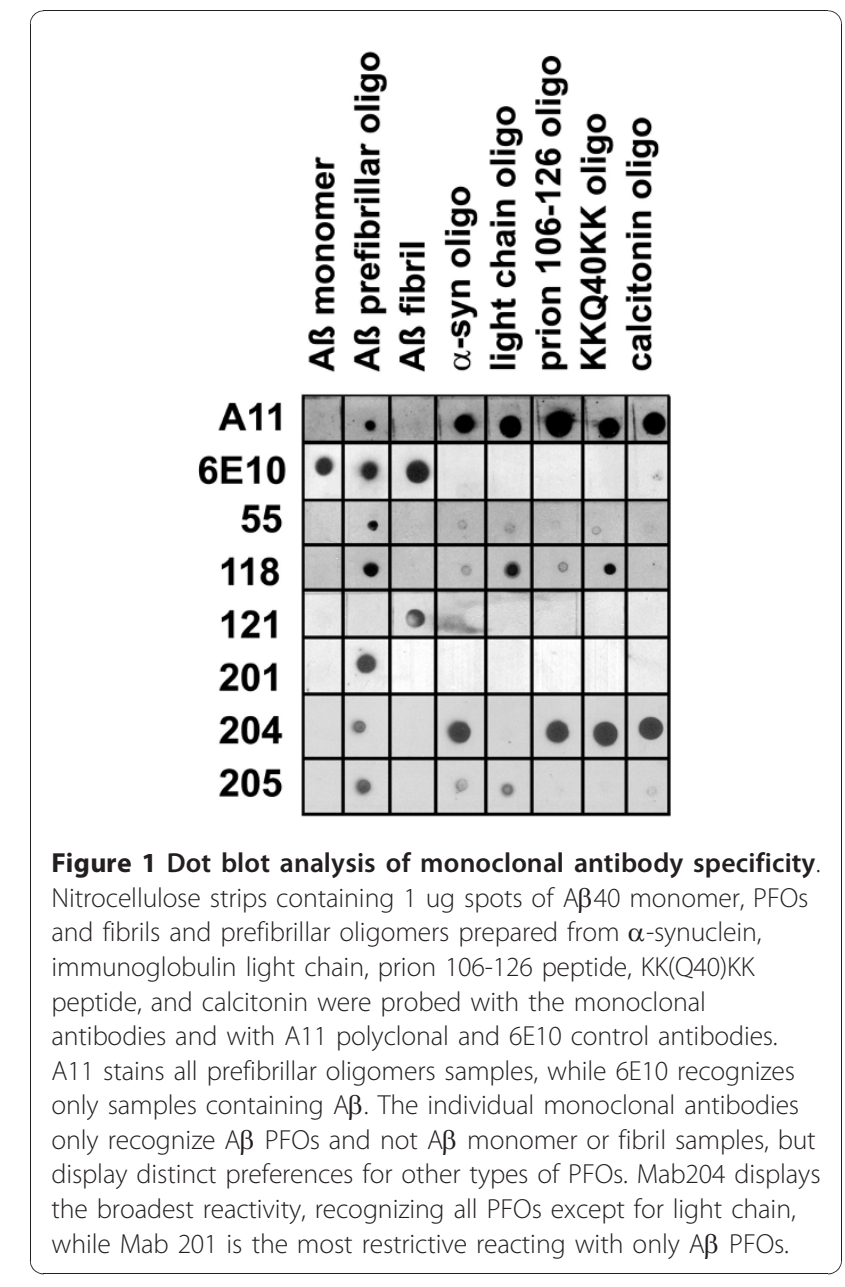

We cloned and sequenced the immunoglobulin heavy and light chains and compared their amino acid sequences (Figure 2A, B). These results indicate that the primary sequences of the 6 monoclonal antibodies are distinct. Mab121 and 201 share a common kappa chain, even though Mab121 is specific for $A \beta$ fibrils, while Mab201 is specific for prefibrillar oligomers. This indicates that the heavy chain is responsible for distinguishing these two conformations of aggregates in 121 and 201. No heavy chain sequence was obtained for 201.

\section{Monoclonal antibodies identify distinct types of $A \beta$ prefibrillar oligomers}

When we examined a large number of A11 positive, $A \beta$ prefibrillar oligomer preparations with the monoclonal IgG antibodies, we observed that some preparations of A11 positive oligomers do not react with some of the monoclonal antibodies, indicating that there are immunologically distinct subclasses of $A \beta$ prefibrillar oligomers (Figure 3). Mab 118 stains both $\mathrm{A} \beta 40$ and $\mathrm{A} \beta 42$ prefibrillar oligomers prepared at $\mathrm{pH} 2.5$, but does not
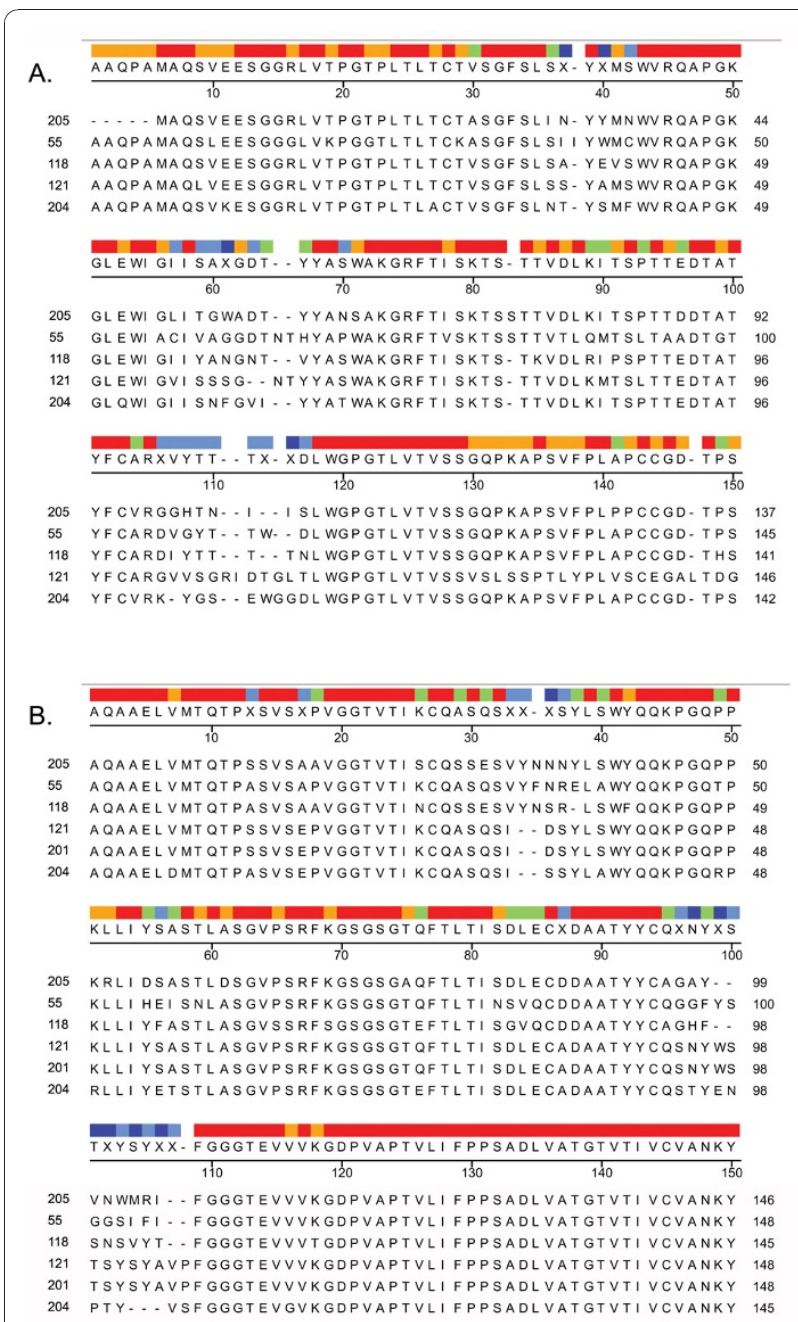

Figure 2 Sequence comparison of monoclonal antibodies. Five monoclonal antibody mRNAs were cloned and sequenced. Alignment of heavy chain (A.) and light chain (B.) variable region amino acid sequences by the Clustal $V$ method is shown. Regions of identical sequence are shown in red, while highly variable regions are shown in blue. Regions of increasing similarity are shown in colors of increasing wavelength.

stain prefibrillar oligomers prepared in Hepes buffered saline (HBS) or phosphate buffered saline (PBS) at $\mathrm{pH}$ 7.4 (Figure 3A), suggesting that the epitope for Mab118 is specific to oligomers prepared at $\mathrm{pH} 2.5$. We also examined a number of different prefibrillar oligomer preparations that were all prepared by the same method: dilution from HFIP solution and incubation in water, $\mathrm{pH}$ 2.5. These preparations were made from the same lot of peptide using the same protocol on different days over a period of approximately one year. Surprisingly, Mab204 and Mab205 display distinct preferences for the different preparations of $A \beta 42$ oligomers, even though they are all A11 positive (Figure 3B). The reason for the lack of reproducibility in oligomer immunoreactivity in 


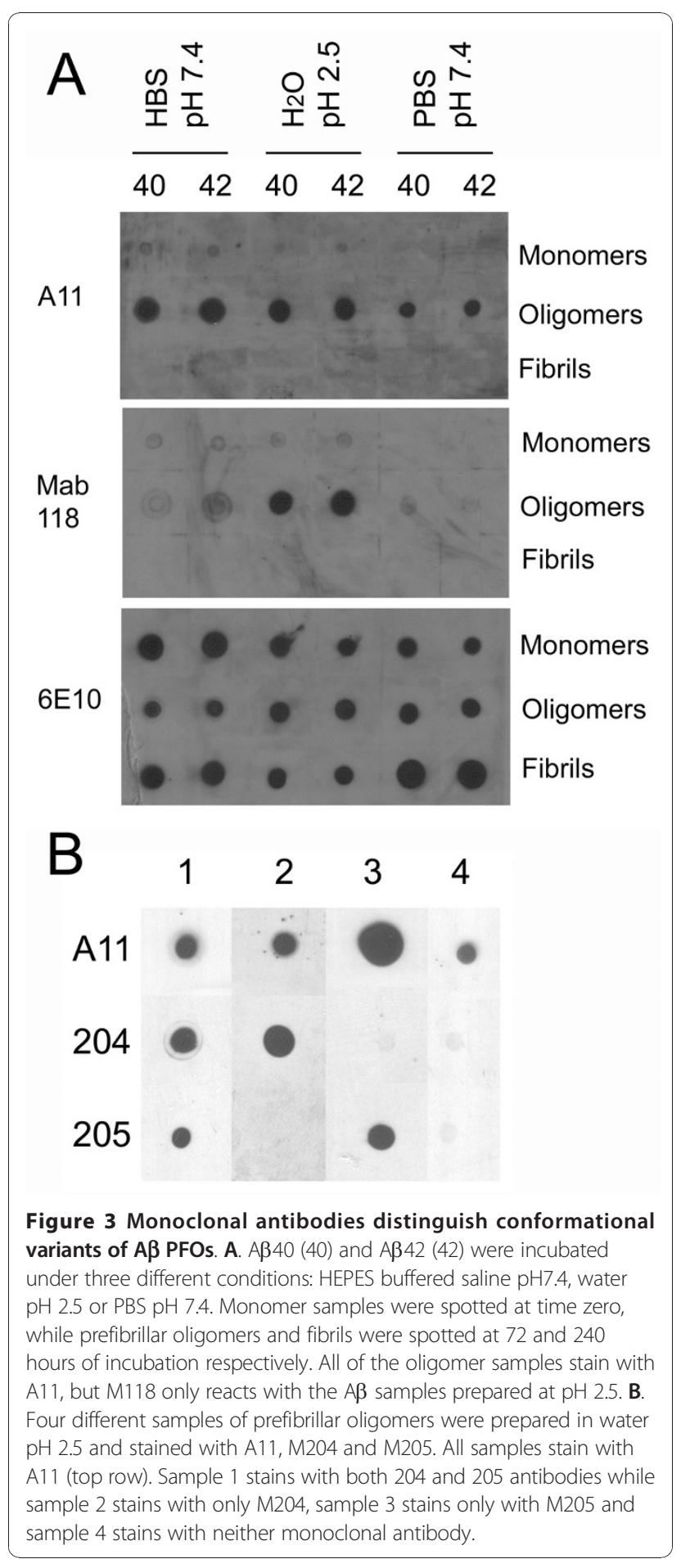

different samples prepared by the same method is not known. These results indicate that there are structural polymorphisms within the class of A11 immunoreactive $A \beta$ prefibrillar oligomers that can be distinguished by the monoclonal antibodies. We have also prepared A11 positive $A \beta$ oligomers that do not react with any of the monoclonal antibodies we have (Figure $3 \mathrm{~B}$ and data not shown), indicating that there are antibodies in polyclonal A11 that are not represented in the clones we obtained. While the epitope recognized by M118 appears to be $\mathrm{pH}$ dependent, it is not yet clear why the immunoreactivities of Mab204 and Mab205 vary because they react differentially with different preparations of $A \beta$ oligomers prepared by the same methods. The variation appears to occur randomly.

\section{Different types of oligomers have distinct size distributions}

Prefibrillar oligomers were prepared from $\mathrm{A} \beta 40$ under two different conditions and analyzed by Western blotting along with freshly prepared monomer. The immunoblots indicate that the monoclonal antibodies recognize distinct size distributions of oligomers (Figure 4A). A11 recognizes a broad range of sizes from a putative dimer of $10 \mathrm{kDa}$ to large oligomers of approximately $240 \mathrm{kDa}$. The individual monoclonals recognize subsets of the bands stained by A11. Mab55 recognizes a ladder of bands ranging from approximately $12 \mathrm{kDa}$ up to approximately $56 \mathrm{kDa}$ (Figure 4A). The apparent step size for the ladder stained by antibody 55 is approximately 2,250 Da. Since the molecular mass of A $\beta 40$ is $4328 \mathrm{Da}$, this suggests that the oligomers migrate artifactually fast on SDS gels and that they contain approximately twice the number of peptide chains than their migration on SDS gels would suggest. A similar ladder-like distribution of $A \beta$ oligomers is also observed with A11[10] although it is not apparent on this blot (see below). Mab118 also stains a $56 \mathrm{kDa}$ band but does not detectably stain a dimer band like Mab 55. Mabs204 and 205 stain a broad band between $35 \mathrm{kDa}$ and $45 \mathrm{kDa}$. The staining of this band by Mab205 is much more intense than that of Mab204. None of the conformation dependent monoclonals or polyclonal antibodies recognize the low molecular weight bands in freshly dissolved $A \beta 40$ preparations (labeled "monomer"), which are recognized by the sequence specific mouse monoclonal antibody 6E10 (Figure 4A). Oligomer preparation 1 contains high molecular weight material migrating at the top of the gel that is stained by the fibril specific polyclonal, $\mathrm{OC}$ and by $6 \mathrm{E} 10$. This material is commonly observed in fibril preparations, but it is not stained by A11 or any of the A11-like monoclonal antibodies, consistent with the observation that these antibodies do not recognize fibrils on dot blots or ELISA. Additionally, oligomer preparation 2 contains low molecular weight FOs recognized by $\mathrm{OC}$ as previously described $[9,10]$. These results indicate that different sized PFOs display unique epitopes associated with distinct size distributions of oligomers that are a subset of the prefibrillar oligomers stained by the polyclonal A11. 


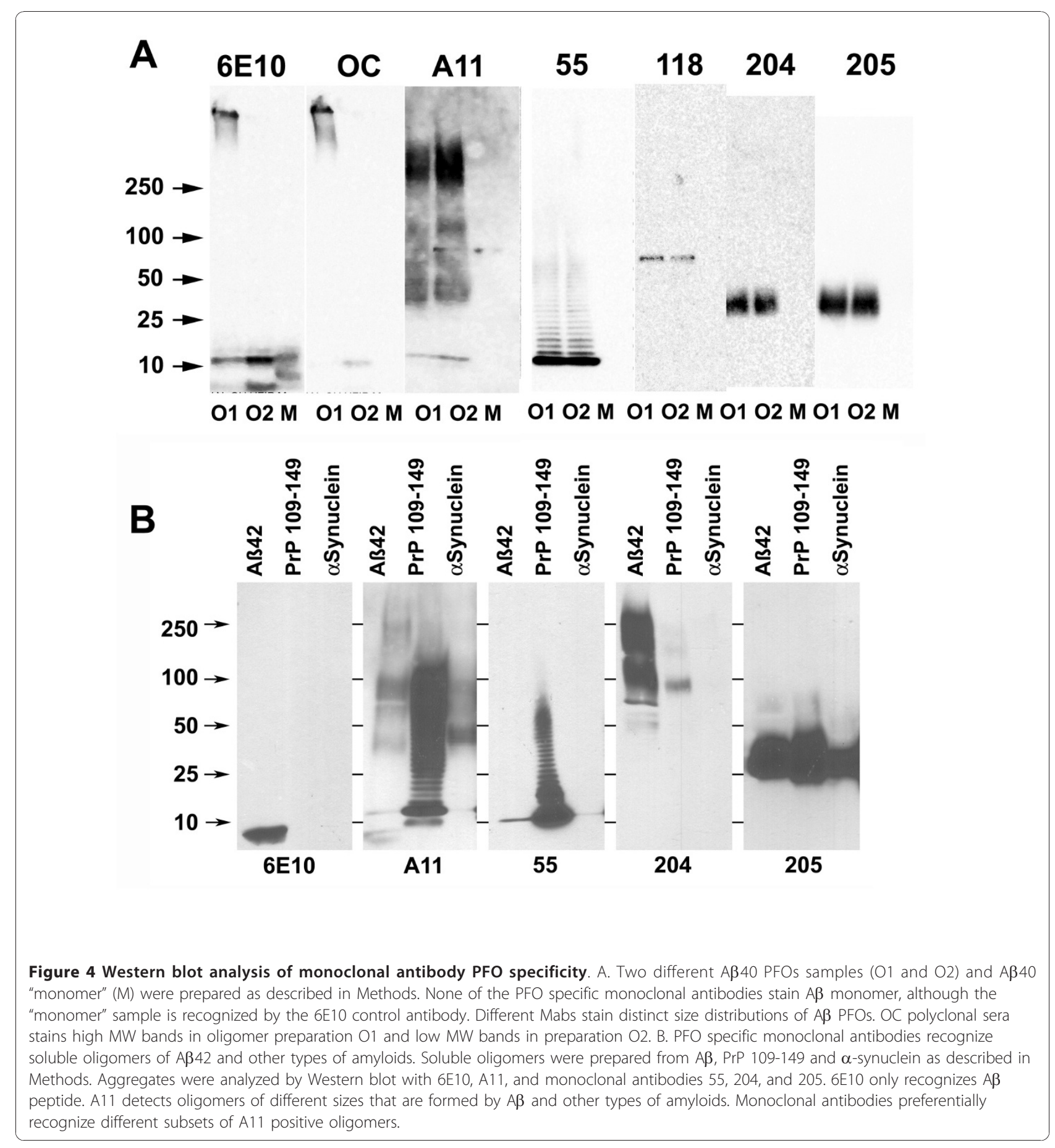

The staining patterns of most of the monoclonal antibodies is the same for the two different preparations of prefibrillar oligomers in Figure 4A, however, Mab204 also stains high molecular weight oligomers in PFOs prepared by dilution of HFIP stock $A \beta 42$ solutions in distilled water and incubated at pH 2.5 (Figure 4B). We also examined the size distribution of PrP 109-149 and $\alpha$-synuclein PFOs. The size distribution of A11 immunoreactivity for $A \beta 42$ is similar to that of $A \beta 40$ (Figure 4A), while PrP109-149 displayed a ladder-like pattern from approximately $10 \mathrm{kDa}$ to $100 \mathrm{kDa}$ and $\alpha$-synuclein PFOs ran as a broad band between $36 \mathrm{kDa}$ and $100 \mathrm{kDa}$. Mab 204 stained high molecular mass bands in A 342 PFOs and a $100 \mathrm{kDa}$ band in PrP109149 PFOs, but did not stain $\alpha$-synuclein oligomers on Western blots, although Mab204 stained $\alpha$-synuclein on 
dot blots (Figure 1). The reason for this differential immunoreactivity is not yet clear, but either the $\alpha$-synuclein oligomers recognized by Mab204 are sensitive to SDS denaturation or there is conformational variability in these two different $\alpha$-synuclein oligomer preparations as we have observed for $A \beta$ (Figure 3B). Mab55 stained a $10 \mathrm{kDa} A \beta 42$ band and a ladder-like series of bands in PrP109-149 that are similar to the pattern observed for A 340 (Figure 4A). Mab205 stained a broad band between approximately 25-45 kDa in A $\beta 42$, PrP109-149 and $\alpha$-synuclein. This identical size distribution of the $\alpha$-synuclein Mab205 immunoreactive species is surprising in view of the fact that the molecular mass of $\alpha$-synuclein is approximately 3-fold higher than $A \beta 42$ or PrP 109-149. No staining was observed with Mab118 (data not shown). While Mabs55 and 205 stain similar patterns of bands in all samples, the size distribution of Mab204 immunoreactivity varies between $A \beta 40$ and A $\beta 42$ samples.

\section{Oligomers seed their own replication}

Western blotting results with the monoclonal IgGs suggest that there are at least two distinct types of A11 immunoreactive $A \beta$ oligomers with different size distributions that occur randomly in oligomer preparations: A ladder-like series ranging in size from approximately $10 \mathrm{kDa}$ to $56 \mathrm{kDa}$ that is recognized by Mab55 and a broad band between $35 \mathrm{kDa}$ and $45 \mathrm{kDa}$ that is recognized by Mab205. We investigated whether these distinct oligomer types can seed the conversion of $A \beta$ monomer into oligomers of the same immunological type and size distribution. The ladder-like oligomers seed the conversion of monomer into the same type of oligomers as indicated by the acceleration of the formation of A11 positive oligomers compared to unseeded monomer controls (Figure 5A). The rate of formation is slow compared to fibril and fibrillar oligomer seeded polymerization [10], reaching a maximum in approximately 8 days. However, no A11 oligomers are observed under these conditions in the unseeded samples. Similar results were obtained when $A \beta 40$ monomer was seeded with $1 \%$ of a preparation of Mab205 positive A $\beta 40$ prefibrillar oligomers that run as a broad band between 35 - $45 \mathrm{kDa}$ (Figure 5B). The presence of seeds promotes the formation of Mab205 positive oligomers compared to monomer samples incubated in the absence of seeds. $A \beta 40$ and $A \beta 42$ 35 - $45 \mathrm{kDa}$ oligomers also seeded the oligomerization of $\mathrm{A} \beta 42$ to form A11 positive oligomers that run as a broad band between $35-45 \mathrm{kDa}$ (Figure $5 \mathrm{C}$ ). The absence of staining of other size bands by A11 indicates that the seeding results in the template specific assembly of a homogeneous population of 35-45 kDa oligomers.

Fibrils and fibrillar oligomers spontaneously form in solutions of $\mathrm{A} \beta 40$ monomer in $\mathrm{H}_{2} \mathrm{O}$ at $\mathrm{pH}$ 7.4 [10].
These fibrillar aggregates are recognized by OC polyclonal antiserum, but not by A11[9]. We examined whether seeding these solutions with PFOs can compete for fibril and fibrillar oligomer formation (Figure 5D). The addition of $1 \%$ PFO seeds completely suppresses the development of $\mathrm{OC}$ positive fibrils and fibrillar oligomers over two days of incubation. Western blot analysis of the samples showed that A11 positive PFOs developed in this sample rather than OC positive fibrils and FOs (data not shown). These results indicate that the presence of PFOs alters the aggregation pathway to favor the formation of PFOs rather than FOs that would normally form in the absence of PFO seeds.

\section{Oligomer specific monoclonal antibodies do not stain plaques}

We also investigated whether the monoclonal IgGs can detect the accumulation of PFOs in human AD brain and Tg2576 and 3xTg-AD transgenic mouse brains. No specific staining of plaque deposits was observed by immunohistochemistry in human AD brain (Figure 6) or transgenic mouse brain (data not shown), indicating that the Mabs do not stain plaques, consistent with their lack of reactivity with amyloid fibrils. It is not yet clear whether the oligomers recognized by these antibodies are absent from human AD or Tg mouse brain tissue. The antibodies exhibit low background reactivity on tissue, indicating that they do not detectably cross react with normal proteins. Further experiments with higher resolution and sensitivity, such as immuno electron microscopy and immunoprecipitation will be necessary to determine whether these oligomers are detectable in vivo.

\section{Discussion}

The prefibrillar amyloid oligomer specific monoclonal antibodies that we have cloned display the canonical features of A11, the corresponding polyclonal antiserum from which they are derived. They recognize epitopes that are specifically associated with prefibrillar oligomers and do not recognize fibrils, fibrillar oligomers, monomer or natively folded proteins. Like A11, the monoclonal IgGs recognize generic epitopes that are displayed on PFOs from several different amyloidogenic sequences, but one of the IgM antibodies, Mab201, recognizes only $A \beta$ PFOs, indicating that some of the epitopes are both conformation and sequence specific. Unlike A11, which displays no obvious sequence preference, the individual monoclonals display distinct preferences for different types of oligomers. All of the monoclonal IgGs react strongly with A $\beta$ PFOs because this preparation was used in the primary screening protocol to select the immunopositive hybridomas. Mab55 appears to be the most selective, because it only reacts 


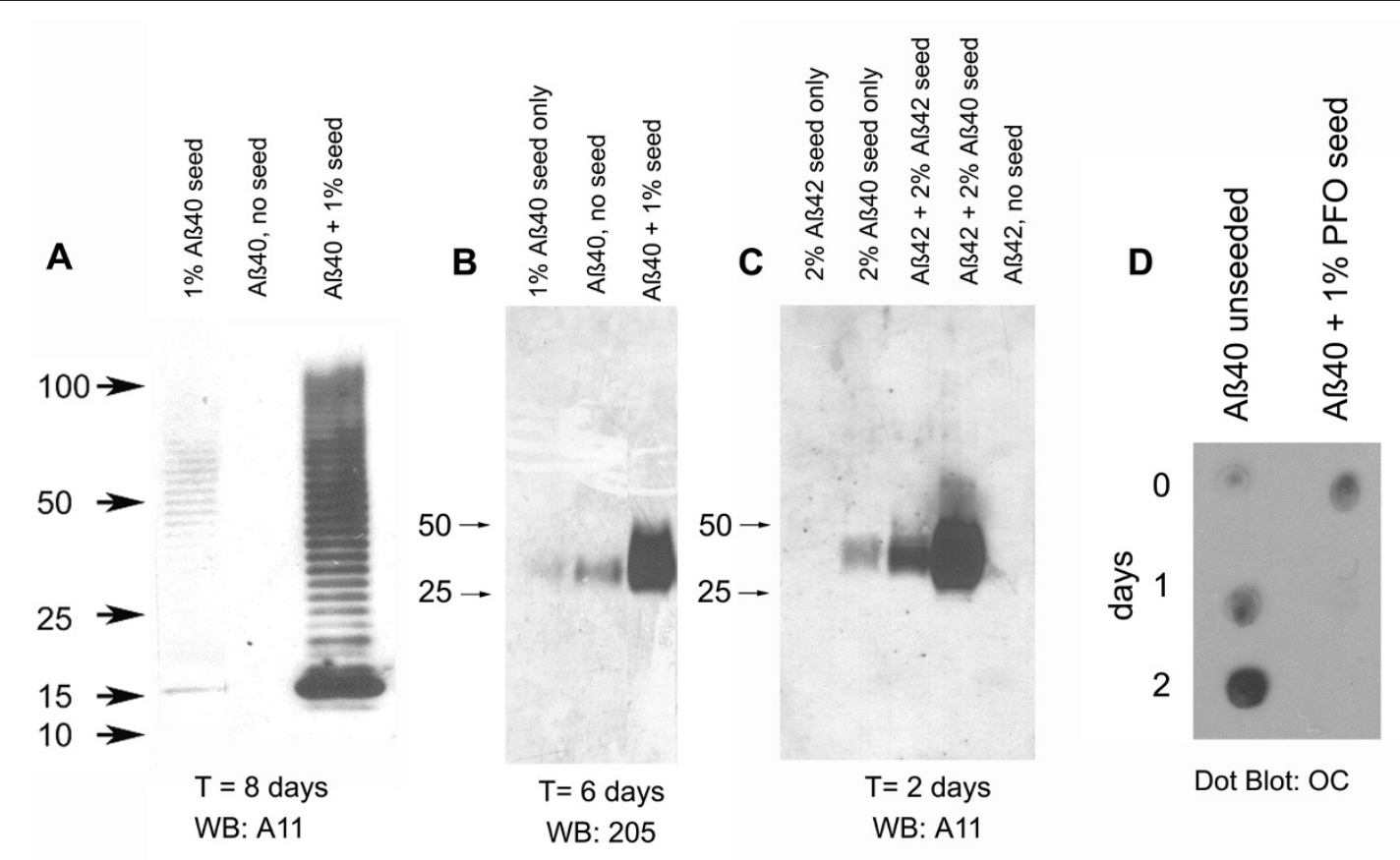

Figure 5 Prefibrillar oligomers seed prefibrillar oligomer formation from monomer. A. The presence of a small amount of ladder like $10-$ $56 \mathrm{kDa}$ PFO seeds (prepared by dilution of $\mathrm{NaOH}$ stock solutions of $\mathrm{A} \beta 40$ into10 mM phosphate buffer pH 7.4), accelerates oligomer formation and gives rise to oligomers that stain with A11. No PFO immunoreactivity is observed in the non-seeded samples under these conditions. B.

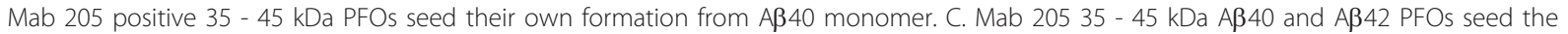
formation of A11 positive $35-45 \mathrm{kDa}$ oligomers from A 42 monomers. Only the $35-45 \mathrm{kDa}$ band is detected by A11, indicating that other sizes of oligomers are not formed. D. Seeding with PFOs suppresses the formation of fibrillar oligomers. In comparison, FOs spontaneously form in unseeded samples.

weakly with other types of PFOs on dot blots. Mab204 appears to have the broadest specificity as it recognizes all types of PFOs strongly except light chain.

The distinct PFO preferences displayed by the monoclonal IgGs would appear to indicate that the antibodies

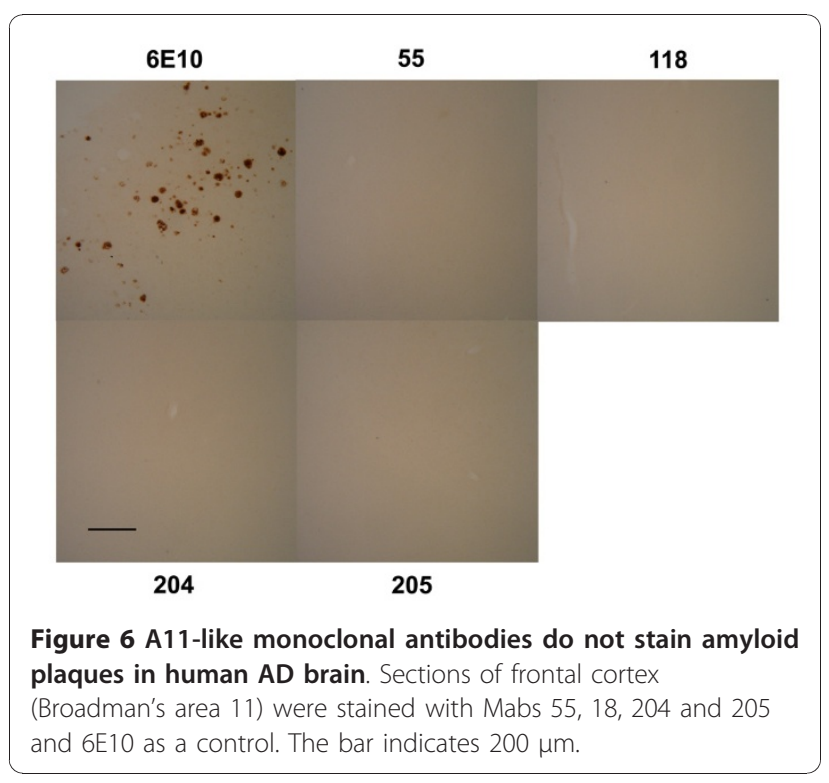

prefer PFOs formed by certain sequences and not others, but further analysis indicates that conformational polymorphism within a sequence is another plausible explanation. The surprising finding is that the same type of immunological variation is observed in different preparations of $A \beta$. This indicates that the different epitopes can be displayed or not by the same sequence depending on the conformation of the peptide and suggests that the $A \beta$ sequence can adopt a number of distinct conformations that may be analogous to the structural polymorphisms in different strains of the yeast prion Sup35 [23]. The variation in detection of $A \beta$ PFOs by Mabs204 and 205 indicates that there are at least three distinct types of PFOs: Mab204+, Mab205+ and a type that is negative for both Mabs that is recognized by A11. The fact that none of the Mabs reacted with this latter preparation of $\mathrm{A} \beta$ PFOs suggests that some of the antibodies represented in A11 have yet to be cloned.

One of the key properties of yeast prions is the ability to replicate and propagate in a template specific fashion [24], so we investigated the ability of $A \beta$ PFOs to seed the conversion of $\mathrm{A} \beta$ monomer in a template specific fashion. We found that both the ladder like Mab55 positive PFOs and the $36 \mathrm{kDa}$ Mab205 positive PFOs are 
capable of accelerating the conversion of $A \beta$ monomer into the same type of PFOs used to seed the reaction, indicating that PFOs also seed in a template specific fashion. Fibrils and fibrillar oligomers are also capable of seeding the conversion of monomer in a template specific fashion $[10,14]$. This indicates that several distinct types of $A \beta$ oligomers exist that have structurally distinct lattices that can facilitate the addition of monomers by intermolecular hydrogen bonding to the ends of the beta sheets. The newly added $A \beta$ peptide adopts the same folded conformation as the peptides serving as the template beneath it extending the intermolecularly hydrogen bonded $\beta$ sheet lattice. The stability of the lattice appears to determine the rate at which the $\mathrm{A} \beta$ oligomers replicate as it does for yeast prions [10]. A $\beta 40$ fibrillar oligomers replicate maximally in approximately 2 hours [10], while $A \beta 40$ PFOs take several days to seed the conversion of monomer into PFOs.

The observation of structurally distinct strains of $A \beta$ prefibrillar oligomers that display different size distributions on Western blots may provide some insight into the structural organization of this class of oligomers. The fact that none of the PFO specific Mabs recognize fibrillar structures that are known to be parallel $\beta$ strands in exact register suggests that PFOs are not parallel beta sheets. The generic epitopes associated with parallel $\beta$ sheet fibrils are recognized by OC polyclonal antibodies that are specific for fibrils and fibrillar oligomers and do not recognize PFOs $[9,10]$. A molten globule like intermediate has been proposed for amyloid aggregation [25-27]. In computer simulations of $A \beta$ peptide aggregation, monomers were observed to rapidly coalesce into a "molten oligomer" ensemble of disordered peptides held together by predominantly hydrophobic interactions and at later times evolve into intermolecularly hydrogen bonded oligomers [28]. It seems unlikely that an ensemble of disordered molten structures would display unique epitopes that the antibodies could discriminate, so this class of oligomer structure does not seem to have the requisite structural diversity to explain all of the types of oligomers observed here. However, the disordered molten oligomer could constitute one of the oligomer subtypes that are not recognized by the conformation dependent antibodies. It has also been suggested that A11 positive PFOs are anti-parallel $\beta$ sheets, based on FTIR spectroscopy [22]. This model provides a facile explanation for the difference between fibrils and fibrillar oligomers, which are parallel beta sheets and PFOs, but it raises the question of the structural basis for the conformational polymorphisms and the molecular nature of the generic epitopes. If PFOs are ordered, antiparallel $\beta$ sheets, then the strands would alternate, giving rise to a linear pattern of alternating amino acid side chains displayed on the surfaces of the sheet. These tracts of alternating side chains could constitute the generic epitopes for the A11 like Mabs, similar to the fashion in which the homogeneous amino side chain tracts may constitute the generic fibril epitopes on parallel in register $\beta$ sheets. Depending on the folding of the sheet, these epitopes may be either hidden or exposed on the surface of the sheet, which could explain the diverse pattern of immunological recognition of $\mathrm{A} \beta$ PFOs by the Mabs.

Alzheimer's disease is known to be clinically and pathologically heterogeneous [29]. Moreover, the role of amyloid in disease is inconsistent with some cognitively normal individuals having large amounts of amyloid plaques, suggesting that not all amyloid is pathologically significant [30]. The findings that amyloid fibrils $[14,16]$ and prefibrillar oligomers display structural heterogeneity suggests that these polymorphisms may underlie the disease heterogeneity and predict that the different structural variants may have distinct toxic activities and pathological significance.

\section{Methods}

\section{Antibody production}

Rabbit monoclonal antibodies were produced under a contract with Epitomics, Incorporated, Burlingame, CA. New Zealand white rabbits were immunized subcutaneously with $A \beta 40$-colloidal gold oligomer mimics at a $0.25 \mathrm{mg} \mathrm{A} \beta$ dose bit and boosted seven times with the same amount at 3 weeks intervals. The titer and specificity of the immune response was determined by ELISA and dot blot analysis as previously described using serum collected after the third and sixth boosts [8]. The ELISA plates and dot blot strips were coated with $50 \mathrm{ng}$ of 5 different samples: $\mathrm{A} \beta$ monomer, $\mathrm{A} \beta$ PFOs, $\mathrm{A} \beta$ fibrils, $\alpha$-synuclein PFOs and islet amyloid polypeptide (IAPP) PFOs. Rabbits demonstrating a serum titer $\geq 0.3$ OD at dilution of 1:64,000 were used as a source of splenocytes for fusion. A11 and 6E10 antibodies were used as positive controls and preimmune serum was used as negative control.

\section{Hybridoma screening}

96 hybridoma pools out of a total of 1920 were selected that were positive for $A \beta 42$ PFOs by ELISA using plates coated with $50 \mathrm{~nm}$ of A 342 PFO. Of this set of 96 pools, 36 pools displayed aggregation state specificity for $\mathrm{A} \beta 42$ PFOs were selected for further analysis by ELISA using plates coated with $A \beta$ monomer, $A \beta$ PFO, $A \beta$ fibrils, $\alpha$-synuclein PFO and IAPP PFO, and dot blotting against $A \beta$ monomer, PFOs, $A \beta$ fibrils and alpha synuclein, light chain, PrP 106-126, KKQ40KK and calcitonin oligomers. Based on these analyses, 6 clones displaying unique immunoreactivities were selected for cloning: 55 , 118, 121, 201, 204 and 205. 


\section{Preparation of $A \beta$ Oligomers}

Lyophilized peptide (A $\beta 40$ or 42 ) was resuspended in $50 \%$ acetonitrile/water mixture and relyophilized. Soluble oligomers were prepared by dissolving $0.3 \mathrm{mg}$ of the peptide in $250 \mu \mathrm{l}$ hexafluoroisopropanol (HFIP) and incubating for 10-20 $\mathrm{min}$ at room temperature. The resulting solution was diluted to $70 \mu \mathrm{M}$ in $\mathrm{H}_{2} \mathrm{O}$ containing $0.02 \% \mathrm{NaN}_{3}$ in a siliconized Eppendorf tube as previously described [8]. In some experiments, the HFIP stock solution was diluted in Hepes buffered saline, $\mathrm{pH}$ 7.4 (HBS) or phosphate buffered saline pH 7.4 (PBS) containing $0.02 \% \mathrm{NaN}_{3}$. The samples were then stirred at 500 RPM using a Teflon-coated micro stir bar for at room temperature. Aliquots were taken at 0-240 hr intervals for testing with anti-oligomer antibody A11 [8]. Alternatively $A \beta 40$ oligomers were prepared by dissolving the lyophilized peptide $(0.3 \mathrm{mg})$ at a concentration of $2.5 \mathrm{mM}$ in $100 \mathrm{mM} \mathrm{NaOH}$. The oligomerization reaction was initiated by diluting the stock solution to $70 \mu \mathrm{M}$ in $10 \mathrm{mM}$ phosphate buffer, $\mathrm{pH} \mathrm{7.4,0.02 \%}$ $\mathrm{NaN}_{3}$. The monomer was prepared by dissolving the $\mathrm{A} \beta$ $40(0.1 \mathrm{mg})$ in $30 \mu \mathrm{l}$ of $10 \% \mathrm{SDS}$, heating at $90^{\circ} \mathrm{C}$ for 5 minutes and diluted to $45 \mu \mathrm{M}$ in $\mathrm{H}_{2} \mathrm{O}$. PrP 109-149, and $\alpha$-synuclein were solubilized in HFIP (hexafluoro-2propanol) at a concentration of $420 \mathrm{uM}$ for 25 minutes at room temperature. Then the peptide solution was diluted into ddH2O, pH 2.5, 0.02\% $\mathrm{NaN}_{3}$ at $70 \mu \mathrm{M}$ and stirred at $500 \mathrm{rpm}$. with a Teflon coated micro stir bar for 2 days. Caps with three 18 gauge needle holes were used to allow slow evaporation of HFIP.

\section{Western and dot blotting}

Samples containing $4 \mu \mathrm{g}$ of A $\beta 42$, PrP 109-149, and $\alpha$-synuclein were dissolved in SDS treatment buffer, boiled for $5 \mathrm{~min}$, and electrophoresed on 10-20\% Tris$\mathrm{HCl}$ (Bio-Rad) gels. Proteins were electrophoretically transferred onto nitrocellulose membranes and developed with $6 \mathrm{E} 10(0.1 \mathrm{ug} / \mathrm{ml}), \mathrm{A} 11(1.05 \mathrm{ug} / \mathrm{ml})$, and monoclonal antibodies $48(1.15 \mathrm{ug} / \mathrm{ml}), 55(0.8 \mathrm{ug} / \mathrm{ml})$, $204(1.05 \mathrm{ug} / \mathrm{ml})$, and 205(0.2 ug/ml). Dot blots and Western blots were performed as previously described [10]. For Western blots, samples containing $4 \mu \mathrm{g}$ of A $\beta 40$ were dissolved in SDS treatment buffer, boiled for $5 \mathrm{~min}$, and electrophoresed on 4-20\% Tris- $\mathrm{HCl}$ (BioRad) gels. Proteins were electrophoretically transferred onto nitrocellulose membranes and developed with conformation-specific antibodies. For dot blots, $0.36 \mathrm{ug}$ of protein was spotted. The concentration of primary antibodies were $6 \mathrm{E} 10(0.1 \mu \mathrm{g} / \mathrm{ml} / \mathrm{ml}), \mathrm{OC}(0.2 \mu \mathrm{g} / \mathrm{ml}), \mathrm{A} 11$ (1.05 $\mu \mathrm{g} / \mathrm{ml}), 48(1.15 \mu \mathrm{g} / \mathrm{ml}), 55(0.8 \mu \mathrm{g} / \mathrm{ml}), 118(0.2 \mu \mathrm{g} /$ $\mathrm{ml}), 204(1.05 \mu \mathrm{g} / \mathrm{ml})$ and $205(0.2 \mu \mathrm{g} / \mathrm{ml})$. The membranes were then incubated with anti-rabbit IgG conjugated with horseradish peroxidase (1:10,000, Jackson) at room temperature for $1 \mathrm{~h}$. The blots were developed with Super signal West pico chemiluminescence kit from Thermo Scientific.

\section{Oligomer seeding}

A 340 peptide $(0.05 \mathrm{mg})$ was dissolved in sodium hydroxide $(0.1 \mathrm{M}, 12 \mu \mathrm{l})$ and incubated for $30 \mathrm{~min}$. The solution was then diluted with sodium phosphate buffer (10 $\mathrm{mM}, \mathrm{pH} 8.0,500 \mu \mathrm{l}$ ), and then seeded with previously prepared A11-positive oligomers $(10 \mu \mathrm{l}, 0.2 \mathrm{mg} / \mathrm{ml}, 4 \%$ by weight). The reaction mixture was incubated at $24^{\circ} \mathrm{C}$ for 2-10 days and assayed for antibody reactivity with Western and dot blots. The diluted $A \beta 40$ solution in the absence of added oligomers was used as a control.

\section{Immunohistochemistry}

Fixed brain tissues (prefrontal cortex) from AD patients were sectioned $(50 \mu \mathrm{m})$ with a vibratome. Coronal sections were collected in PBS (containing 0.02\% sodium azide) and stored at $4{ }^{\circ} \mathrm{C}$ prior to staining. To stain for A $\beta$ plaques, sections were immersed in $70 \%$ formic acid for $5 \mathrm{~min}$. Endogenous peroxidase in tissue was blocked by treating with $3 \% \mathrm{H}_{2} \mathrm{O}_{2}$ in $\mathrm{PBS}$ for $10 \mathrm{~min}$ at room temperature. Nonspecific background staining was blocked by $1 \mathrm{~h}$ incubation in $2 \%$ BSA, $0.3 \%$ Triton $\mathrm{X}-100$ (TX) at room temperature. Tissues were incubated with primary antibodies $6 \mathrm{E} 10(0.2 \mu \mathrm{g} / \mathrm{ml}), 55(3.2$ $\mu \mathrm{g} / \mathrm{ml}), 118(1.6 \mu \mathrm{g} / \mathrm{ml}), 204(4.8 \mu \mathrm{g} / \mathrm{ml})$ and $205(4 \mu \mathrm{g} /$ $\mathrm{ml}$ ) for $48 \mathrm{hrs}$ at $4^{\circ} \mathrm{C}$, rinsed 3 times with PBS,0.1\% TX, followed by biotinylated secondary antibodies (antimouse for 6E10 and anti-rabbit for rabbit antibodies), detection with an $\mathrm{ABC}$ peroxidase kit, and visualization with a 3,3'-diaminobenzidine (DAB) substrate kit (Vector, Burlingame, CA).

\section{Acknowledgements}

Supported by NIH NS 31230, NIH/NIA ADRC P50 AG16573 and NIH/NIA P01 AG000538, NIH NS045283, the Cure Alzheimer's Fund and the Larry L. Hillblom Foundation.

\section{Author details}

'Department of Molecular Biology and Biochemistry, University of California, Irvine, CA 92697-3900, USA. ${ }^{2}$ Department of Pharmacology, University of California San Diego La Jolla, CA 92093-0636, USA. ${ }^{3}$ Departments of Developmental and Cell Biology, Pharmacology and the Developmental Biology Center, University of California, Irvine, CA 92697-3900, USA. ${ }^{4}$ SandersBrown Center on Aging, University of Kentucky, Lexington, KY, 40536-0230, USA. ${ }^{5}$ Department of Neurology, University of Texas Medical Branch, Galveston, TX 77555-0144, USA.

\section{Authors' contributions}

RK prepared the antigens and oligomer samples and did the initial screening and characterization of the monoclonal antibodies. SY prepared antibodies and characterized them. EH, and RA did the

immunohistochemistry on transgenic mouse and human AD tissue. JW, LB, AP, IC and SR prepared oligomer samples and conducted the dot blot and Western blot analysis of the samples. LM and TL cloned and sequenced the heavy and light chain CDNAs. CG participated in concept, design, data analysis and manuscript preparation. All authors read and approved the final manuscript. 


\section{Competing interests}

The authors declare that they have no competing interests.

Received: 20 August 2010 Accepted: 13 December 2010

Published: 13 December 2010

\section{References}

1. Terry RD: The pathogenesis of Alzheimer disease: an alternative to the amyloid hypothesis. J Neuropathol Exp Neurol 1996, 55(10):1023-1025.

2. Westerman MA, Cooper-Blacketer D, Mariash A, Kotilinek L, Kawarabayashi T, Younkin LH, Carlson GA, Younkin SG, Ashe KH: The relationship between Abeta and memory in the Tg2576 mouse model of Alzheimer's disease. J Neurosci 2002, 22(5):1858-1867.

3. Billings LM, Oddo S, Green KN, McGaugh JL, Laferla FM: Intraneuronal Abeta causes the onset of early Alzheimer's disease-related cognitive deficits in transgenic mice. Neuron 2005, 45(5):675-688.

4. McLean CA, Cherny RA, Fraser FW, Fuller SJ, Smith MJ, Beyreuther K, Bush Al, Masters CL: Soluble pool of Abeta amyloid as a determinant of severity of neurodegeneration in Alzheimer's disease. Annals of Neurology 1999, 46(6):860-866.

5. Lue LF, Kuo YM, Roher AE, Brachova L, Shen Y, Sue L, Beach T, Kurth JH, Rydel RE, Rogers J: Soluble amyloid beta peptide concentration as a predictor of synaptic change in Alzheimer's disease. American Journal of Pathology 1999, 155(3):853-862.

6. Baglioni S, Casamenti F, Bucciantini M, Luheshi LM, Taddei N, Chiti F, Dobson CM, Stefani M: Prefibrillar amyloid aggregates could be generic toxins in higher organisms. J Neurosci 2006, 26(31):8160-8167.

7. Haass C, Selkoe DJ: Soluble protein oligomers in neurodegeneration: lessons from the Alzheimer's amyloid beta-peptide. Nat Rev Mol Cell Biol 2007, 8(2):101-112

8. Kayed R, Head E, Thompson JL, McIntire TM, Milton SC, Cotman CW, Glabe CG: Common structure of soluble amyloid oligomers implies common mechanism of pathogenesis. Science 2003, 300(5618):486-489.

9. Kayed R, Head E, Sarsoza F, Saing T, Cotman CW, Necula M, Margol L, Wu J, Breydo L, Thompson JL, et al: Fibril specific, conformation dependent antibodies recognize a generic epitope common to amyloid fibrils and fibrillar oligomers that is absent in prefibrillar oligomers. $\mathrm{Mol}$ Neurodegener 2007, 2(18):18.

10. Wu JW, Breydo L, Isas JM, Lee J, Kuznetsov YG, Langen R, Glabe C: Fibrillar Oligomers Nucleate the Oligomerization of Monomeric Amyloid \{beta\} but Do Not Seed Fibril Formation. J Biol Chem 2010, 285(9):6071-6079.

11. Kayed R, Pensalfini A, Margol L, Sokolov Y, Sarsoza F, Head E, Hall J, Glabe C: Annular protofibrils are a structurally and functionally distinct type of amyloid oligomer. J Biol Chem 2009, 284(7):4230-4237.

12. Tycko R: Molecular structure of amyloid fibrils: insights from solid-state NMR. Q Rev Biophys 2006, 39(1):1-55.

13. Margittai M, Langen R: Fibrils with parallel in-register structure constitute a major class of amyloid fibrils: molecular insights from electron paramagnetic resonance spectroscopy. Q Rev Biophys 2008, 41(34):265-297.

14. Petkova AT, Leapman RD, Guo Z, Yau WM, Mattson MP, Tycko R: Selfpropagating, molecular-level polymorphism in Alzheimer's beta-amyloid fibrils. Science 2005, 307(5707):262-265.

15. Luhrs T, Ritter C, Adrian M, Riek-Loher D, Bohrmann B, Dobeli H, Schubert D, Riek R: 3D structure of Alzheimer's amyloid-beta(1-42) fibrils. Proc Natl Acad Sci USA 2005, 102(48):17342-17347.

16. Kodali R, Williams AD, Chemuru S, Wetzel R: Abeta(1-40) forms five distinct amyloid structures whose beta-sheet contents and fibril stabilities are correlated. J Mol Biol 2010, 401(3):503-517.

17. Paravastu AK, Leapman RD, Yau WM, Tycko R: Molecular structural basis for polymorphism in Alzheimer's beta-amyloid fibrils. Proc Natl Acad SCi USA 2008, 105(47):18349-18354

18. Shewmaker F, Wickner RB, Tycko R: Amyloid of the prion domain of Sup35p has an in-register parallel beta-sheet structure. Proc Natl Acad Sci USA 2006, 103(52):19754-19759.

19. Wickner RB, Dyda F, Tycko R: Amyloid of Rnq1p, the basis of the [PIN+] prion, has a parallel in-register beta-sheet structure. Proc Natl Acad Sci USA 2008, 105(7):2403-2408.

20. Shewmaker F, Kryndushkin D, Chen B, Tycko R, Wickner RB: Two prion variants of Sup35p have in-register parallel beta-sheet structures, independent of hydration. Biochemistry 2009, 48(23):5074-5082.
21. Török M, Milton S, Kayed R, Wu P, McIntire T, Glabe CC, Langen R: Structural and dynamic features of Alzheimer's Abeta peptide in amyloid fibrils studied by site-directed spin labeling. J Biol Chem 2002, 13:13.

22. Cerf E, Sarroukh R, Tamamizu-Kato S, Breydo L, Derclaye S, Dufrene YF, Narayanaswami V, Goormaghtigh E, Ruysschaert JM, Raussens V: Antiparallel beta-sheet: a signature structure of the oligomeric amyloid beta-peptide. Biochem J 2009, 421(3):415-423.

23. Toyama BH, Kelly MJ, Gross JD, Weissman JS: The structural basis of yeast prion strain variants. Nature 2007, 449(7159):233-237.

24. Tanaka M, Collins SR, Toyama BH, Weissman JS: The physical basis of how prion conformations determine strain phenotypes. Nature 2006, 442(7102):585-589.

25. Gerber R, Tahiri-Alaoui A, Hore PJ, James W: Oligomerization of the human prion protein proceeds via a molten globule intermediate. J Biol Chem 2007, 282(9):6300-6307.

26. Campioni S, Mossuto MF, Torrassa S, Calloni G, de Laureto PP, Relini A, Fontana A, Chiti F: Conformational properties of the aggregation precursor state of HypF-N. J Mol Biol 2008, 379(3):554-567.

27. Liang Y, Lynn DG, Berland KM: Direct observation of nucleation and growth in amyloid self-assembly. J Am Chem Soc 132(18):6306-6308.

28. Cheon M, Chang I, Mohanty S, Luheshi LM, Dobson CM, Vendruscolo M, Favrin G: Structural reorganisation and potential toxicity of oligomeric species formed during the assembly of amyloid fibrils. PLOS Comput Biol 2007, 3(9):1727-1738.

29. Hansen LA, Masliah E, Terry RD, Mirra SS: A neuropathological subset of Alzheimer's disease with concomitant Lewy body disease and spongiform change. Acta Neuropathol (Berl) 1989, 78:194-201.

30. Katzman R, Terry R, DeTeresa R, Brown T, Davies P, Fuld P, Renbing X, Peck A: Clinical, pathological, and neurochemical changes in dementia: a subgroup with preserved mental status and numerous neocortical plaques. Ann Neurol 1988, 23(2):138-144.

doi:10.1186/1750-1326-5-57

Cite this article as: Kayed et al: Conformation dependent monoclonal antibodies distinguish different replicating strains or conformers of prefibrillar A $\beta$ oligomers. Molecular Neurodegeneration 2010 5:57.

\section{Submit your next manuscript to BioMed Central and take full advantage of:}

- Convenient online submission

- Thorough peer review

- No space constraints or color figure charges

- Immediate publication on acceptance

- Inclusion in PubMed, CAS, Scopus and Google Scholar

- Research which is freely available for redistribution 